\title{
Programa de tutoría Cálculo Diferencial e Integral I: éxito y permanencia
}

\author{
Kelly Amorim Gomes \\ Licenciada en Matemáticas y \\ Especialista en Psicología Clínica e Institucional \\ Centro Universitario La Salle, Canoas. Estudiante de Maestría en \\ Educación del programa de Posgrado en Educación en el Centro \\ Universitario La Salle (Canoas), Brasil. \\ kelly.amorimgomes@gmail.com
}

\author{
Vera Lucia Felicetti \\ Doctora en Educación y \\ Maestría en Educación en Ciencias y Matemáticas \\ Pontificia Católica del Río Grande del Sur. Profesora del programa de \\ Posgrado en Educación en el Centro \\ Universitario La Salle (Canoas), Brasil. \\ verafelicetti@ig.com.br
}

Cómo citar este artículo:

Amorim, K. y Felicetti, V. (2015). Programa de tutoría Cálculo Diferencial e Integral I: éxito y permanencia. Espiral, Revista de Docencia e Investigación, 5(1), 93-100

\section{Resumen}

Este artículo, de carácter reflexivo, tiene como objetivo presentar el trabajo desarrollado en las tutorías iniciadas en el primer semestre de 2013. El abordaje metodológico usado fue cuantitativo con enfoque descriptivo comparativo. Los datos analizados abarcaron información obtenida de los estudiantes de pregrado inscritos en la asignatura de Cálculo Diferencial e Integral I, en el primer y segundo semestre del 2013 y primer semestre de 2014, de una universidad en el sur de Brasil, que frecuentaran o no los espacios de tutoría fuera o dentro del salón de clase. Los resultados del análisis indican el gradual crecimiento de los índices de aprobación de los estudiantes, luego de su participación en el programa de Tutoría con el acompañamiento de una licenciada en matemáticas - tutora titular. Los resultados muestran la necesidad e importancia del trabajo preventivo, en el que, tanto la institución como los docentes y estudiantes, se movilizan las estrategias pertinentes para lograr el éxito académico y, por ende, su permanencia en la institución hasta la graduación.

Palabras clave: Enseñanza; aprendizaje; tutoría; cálculo diferencial e integral.

\section{Abstract}

This reflection paper aims to present the work done in tutorials sessions that started in the first half of 2013. The methodological approach used was quantitative with a comparative descriptive approach. The analyzed data cover information from the undergraduate students enrolled in the course Differential and Integral Calculus I, in the first and second half of 2013 and first half of 2014 at a university in southern Brazil, even though these students frequented or not tutoring spaces outside or inside classroom. The analysis results show the gradual growth of the students' passing rates after participating in the tutorial program with the accompanied by a Bachelor in Mathematics - tutor holder. The results show the need and importance of doing preventive work, in which the institution, the teachers as well as the students mobilize relevant strategies to achieve academic success and therefore ensure the students' permanence in the institution until graduation.

Keywords: Education; learning; tutorial; differential and integral calculus.

\section{Introducción}

La preocupación con el acceso a la educación superior brasileña no es reciente (Rossato, 2006). El número de estudiantes matriculados en educación superior ha aumentado significativamente desde el final de la década de los ochenta (Felicetti, Fossatti, 2014). Sin embargo, de acuerdo con el MEC/INEP/DEED (2013), no hay un aumento proporcional de los graduados, lo que demuestra que muchos estudiantes no se quedaron o no permanecen en la educación superior desde el acceso hasta su graduación.

Esto sugiere que a medida que el acceso a la educación superior aumenta también aumentan los problemas relacionados con la deserción y la permanencia de los estudiantes en este nivel de educación. Ante esta situación, 
parece que medir las tasas de deserción es de suma importancia, pero solo medir estos índices no refleja la resolución de problemas relacionados con la deserción.

Junto con el aumento de la oferta y la demanda de cursos de Licenciatura de Ingeniería en el Centro Universitario La Salle Centro (Unilasalle) situado en Canoas en Río Grande del Sur - Brasil, también se observa el creciente número de estudiantes con dificultad en los requisitos previos acerca de los contenidos de la enseñanza básica, especialmente en asignaturas que involucran las matemáticas.

Según Felicetti y Giraffa (2012), “La enseñanza de las matemáticas se estructura en una cadena de requisitos previos de educación básica a la educación superior. Si uno de los enlaces de esta cadena es frágil compromete todo el sistema" (p. 143).

Cury (2004) indica que:

A menudo comentamos, en las reuniones o conferencias, el bajo nivel de conocimientos matemáticos con los que vienen los estudiantes a la universidad. Sin embargo, incluso si tratamos de atribuir la responsabilidad a los niveles anteriores de educación (con el riesgo de llegar a "culpar"a la primera infancia por los problemas), sabemos que estos son los estudiantes que tenemos y nuestra responsabilidad -y desafío- es llevarlos a desarrollar las habilidades necesarias para compensar las dificultades que se presentan mientras buscamos despertar en ellos el deseo de descubrir las respuestas a sus dudas (pp. 123-124).

Las dificultades relacionadas con el conocimiento de los conceptos básicos en matemáticas, observados en la asignatura de Matemática Elemental, son aún más evidentes en la asignatura de Cálculo Diferencial e Integral I, en la que se presenta como uno de los grandes villanos en el escenario de reprobación y deserción en los primeros semestres de las ingenierías.

Dadas las fuertes dificultades de aprendizaje presentes en la vida académica de los estudian- tes de Cálculo Diferencial e Integral I y, conscientes de que la responsabilidad por el fracaso de los estudiantes no solo son suyas o de sus maestros, se señala la necesidad de trabajar con medidas preventivas y de seguimiento a los alumnos dentro de la educación superior, es decir, estrategias de apoyo institucional.

En esta perspectiva la Unilasalle ha ofrecido más que actividades aisladas, un programa de apoyo para el estudiante, que comprende: talleres, tutorías, tutoría en el salón de clase, consejos y atención psicológica.

En este documento se presentará la dinámica desarrollada por la institución a través del Centro de Apoyo al Estudiante (NAE') destacando el seguimiento a la tutoría desarrollada en el Área de Ciencias Exactas, específicamente en la asignatura de Cálculo Diferencial e Integral I, que tuvo lugar en el salón de clases junto con el profesor de la asignatura. En la segunda parte de este artículo se explica la metodología utilizada en el estudio; el análisis de los datos; las consideraciones finales y por último las referencias.

\section{Tutoría en el salón de clase}

El servicio de tutoría es una de las actividades que ofrece el NAE. Este núcleo se caracteriza por el seguimiento en su curso académico en la institución, buscando una mayor comprensión de las situaciones individuales y colectivas, con el fin de colaborar con un mejor rendimiento académico, lo que garantiza la permanencia en la institución hasta graduarse.

La tutoría tiene como objetivos atender a los estudiantes de la Institución para rescatar sus dificultades, tanto en el contenido trabajado en clase, como de los requisitos previos, o sea, aquellos de la secundaría, desarrollando de esta manera, estrategias de enseñanza y aprendizaje capaces de disminuir o incluso resolver las dificultades presentadas por los estudiantes.

1 Núcleo de Apoio ao Estudante (NAE). 


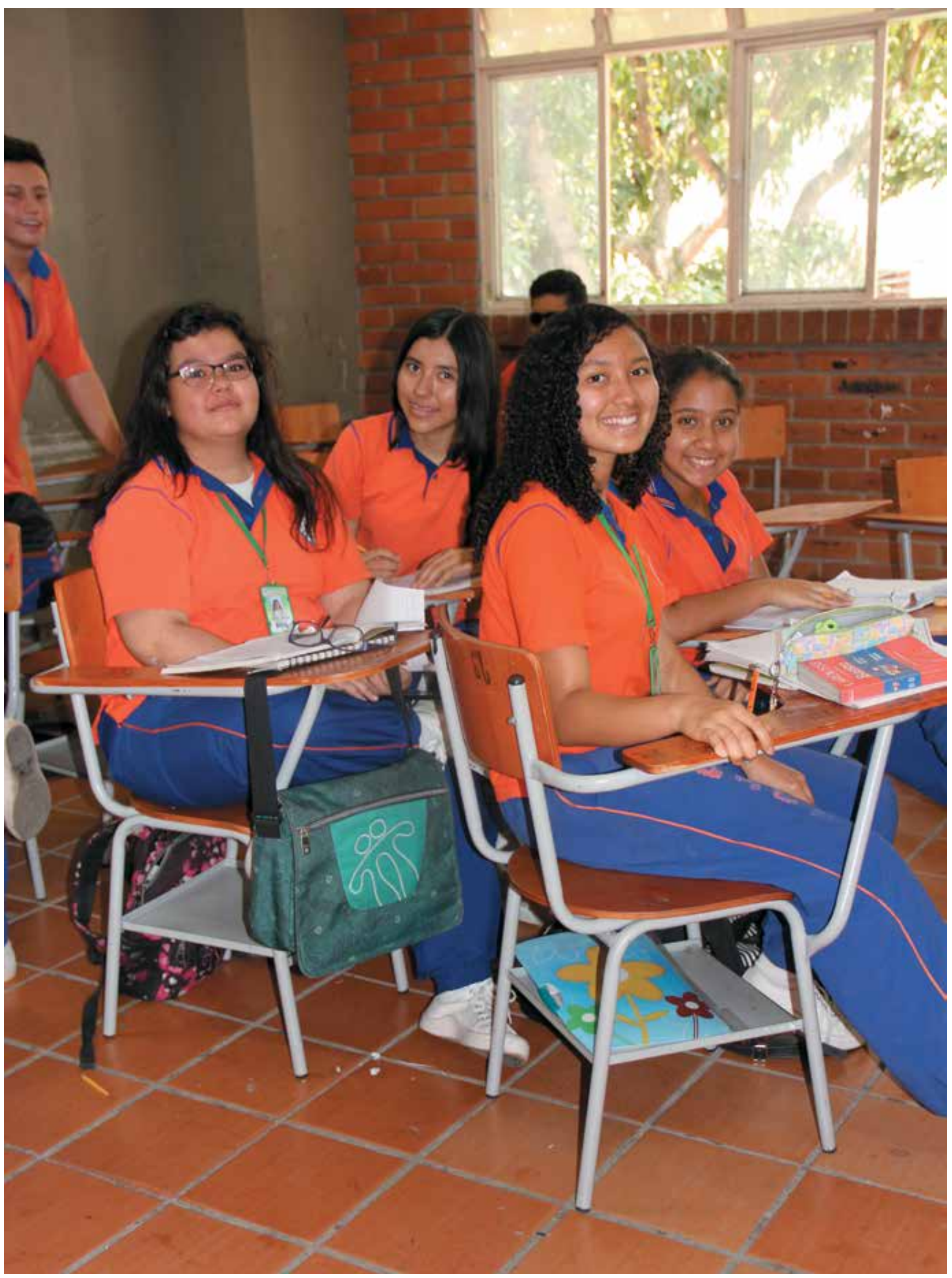


El papel de los tutores de la Institución es ayudar a los estudiantes con sus preguntas y dudas, relacionadas con el contenido trabajado por el profesor en la clase, incluso, si tiene que ver con los contenidos de las matemáticas, considerados previos para este nivel de enseñanza. Los estudiantes obtienen respuestas a sus dudas, explicaciones del contenido cuando faltan a la clase y ayuda para resolver los ejercicios propuestos por el profesor. Los tutores reciben apoyo de los profesores, que proporcionan el material trabajado en clase y en algunas situaciones la liberación del sitio virtual de la signatura para que el tutor pueda ampliar su participación en ella.

En este artículo nos centramos en hablar sobre el programa de Tutoría que se ofrece en el salón de clase, incluso con el profesor de Cálculo Diferencial e Integral I. Este programa cuenta con una tutora contratada por el NAE. Ella es denominada monitora titular, con formación en matemáticas y trabaja 40 horas en la Institución, atendiendo a los estudiantes, incluso con horas programadas.

La función de la tutora titular en la clase de Cálculo es ayudar a los estudiantes con sus dudas respecto de los ejercicios propuestos por el profesor en la signatura, pues las clases de cálculo, por lo general, tienen un promedio de 45 estudiantes, que pone de relieve la necesidad de un tutor que acelere el proceso de clarificación de las dudas, mientras el maestro cumple su función como docente, o sea, tanto el docente como la tutora ayudan a los estudiantes en la resolución de los ejercicios en clase. La tutora es como un docente asistente que trabaja junto con el docente titular.

A continuación se explica la metodología utilizada en el análisis de los datos.

\section{Metodología}

Este estudio tiene enfoque cuantitativo como abordaje metodológico y el objetivo es descriptivo comparativo. Para Gay, Mills y Airasian (2009) la investigación cuantitativa se constituye en "una colección y análisis de datos que permitan describir, explicar, predecir o controlar todo fenómeno de interés" (p. 7). El propósito descriptivo, según Silva y Menezes (2001), hace que sea posible describir las características de la población o fenómeno en el enfoque o el establecimiento de relaciones entre las variables en cuestión, en este estudio la población son los estudiantes de las clases donde la tutora estuvo presente y aquellos que tuvieron la tutoría fuera de la clase.

El trabajo desarrollado por la tutora titular en el primer semestre de 2014 se registró a partir del acta de presencia en dos clases de Cálculo Diferencial e Integral I en los días de lunes por la tarde y sábado por la mañana.

También se realizaron registros de asistencia de tutoría programada para la signatura de Cálculo Diferencial e Integral I, es decir, del proceso tutorial desarrollado con los estudiantes fuera del espacio de clase de la asignatura. Así se creó una base de datos con la cual fue posible analizar la participación en la tutoría, vinculada a la presencia de la tutora en clase. También fueron usados datos de los registros de participación de los estudiantes en la tutoría del 2013, como estrategia para percibir si en efecto la tutoría en clase ha impactado en el desempeño de los estudiantes en la signatura de Cálculo Diferencial e Integral I.

A partir de las informaciones evidenciadas en los registros, se construyeron tablas que permitieron contabilizar la cantidad de procesos tutoriales realizados y el número de estudiantes atendidos. En la secuencia se verificó el rendimiento académico de los estudiantes en la asignatura en los diferentes días de clase.

\section{Análisis y discusión de los datos}

En la figura 1 podemos observar el rendimiento de los estudiantes matriculados en la 
asignatura de Cálculo Diferencial e Integral I, en el primer y segundo semestre de 2013 y el primer semestre de 2014. Tuvimos 101 alumnos matriculados en Cálculo Diferencial e Integral I, en el primer semestre de 2013, 105 en el segundo semestre de 2013 y 130 estudiantes en el primer semestre de 2014.

Los resultados muestran que hubo un incremento gradual en el porcentaje y el número de estudiantes que aprobaron sus semestres. En el primer semestre de 2013 ascendió a 40 (39.6\%) estudiantes exitosos, 45 (42.86\%) en el segundo semestre de 2013 y 62 (47.69\%) estudiantes en el primer semestre de 2014.

Además, hubo una reducción progresiva en el porcentaje de estudiantes que no aprobaron. Los alumnos que no han obtenido el promedio final de menos de 6, fueron 33 (32.67\%) en el primer semestre de 2013, en el segundo 32 (30.48\%) estudiantes y 37 (28.46\%) en el primero de 2014. Los estudiantes que no lograron aprobar la asignatura debido a inasistencias prolongadas, bloqueo de la asignatura ${ }^{2}$, retirada o cancelación, ascendió a un total de 28 (27.7\%) de los estudiantes en el primer semestre de 2013, 27 (25.71\%) en el segundo semestre de 2013 y 31 (23.84\%) en el primer semestre de 2014.

Aunque las diferencias son pequeñas de un semestre a otro, se observa que esta proporción ha ido disminuyendo, lo que refuerza la necesidad de una labor de apoyo a los estudiantes. Cabe señalar que también hubo un aumento constante en el número de alumnos matriculados en el curso a lo largo de los semestres analizados.

En la figura 2 se observa el desempeño de los estudiantes matriculados en Cálculo Diferencial e Integral I, en el primer semestre de 2014, al hacer una comparación entre las clases lunes por la noche, martes por la noche $y$ la mañana del sábado. Los datos apuntan a 48 alumnos matriculados en la clase del lunes, 45 inscritos en la clase del martes y 37 en la clase del sábado.

2 Es el estudiante que se detiene en medio del semestre, es decir, renuncia a continuar en la asignatura.

Figura 1. Estadística general del rendimiento en la signatura de Cálculo Diferencial e Integral I

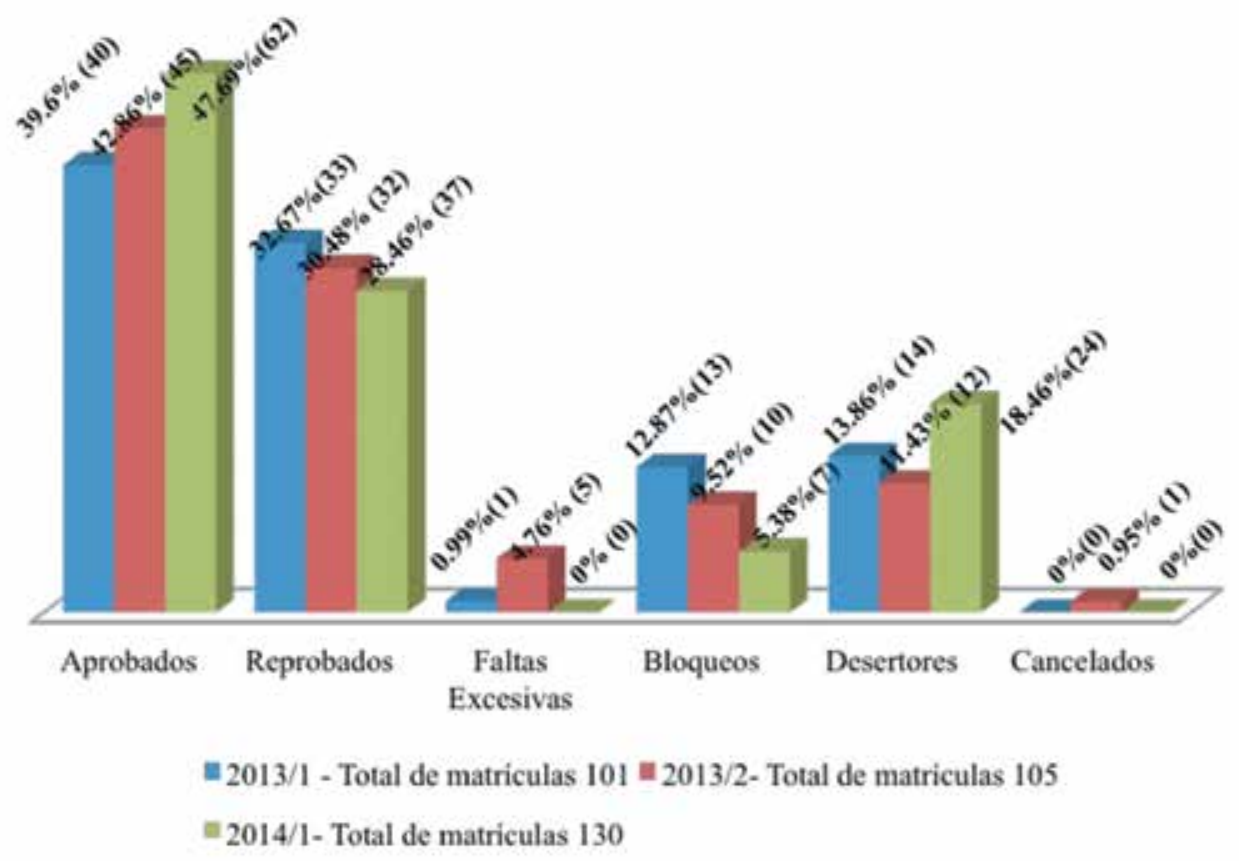


Figura 2. Estadística general del rendimiento en la signatura de Cálculo Diferencial e Integral l en 2014/1

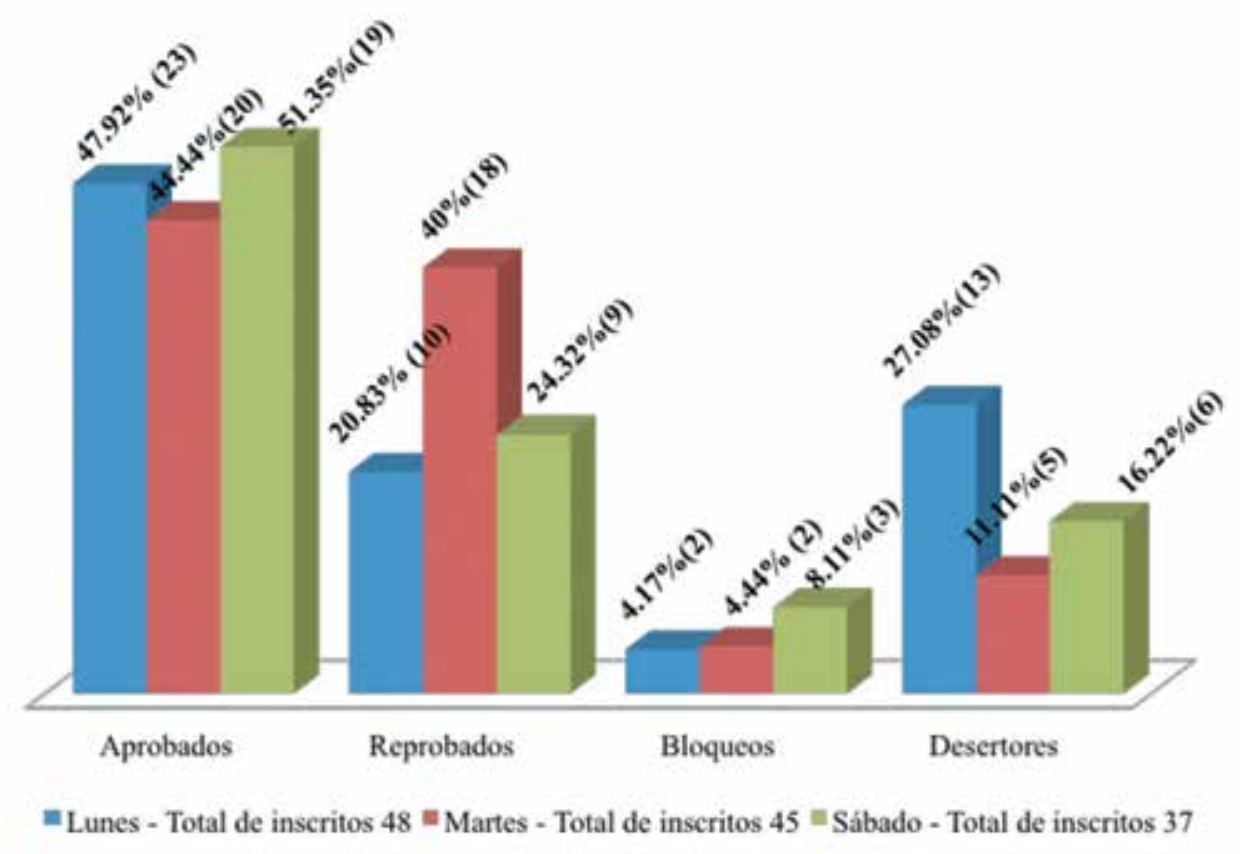

Fuente: Registros del NAE - 2014/1.

Como se observa en la figura 2, los porcentajes de aprobación fueron mayores en las clases del lunes (47.92\%) y sábado (51.35\%) en comparación con el martes (44.44\%). También podemos observar que el porcentaje de reprobación (40\%) en la clase del martes fue mayor en comparación con los otros dos grupos, que era $20.83 \%$ el lunes y $24.32 \%$ el sábado. El número total de estudiantes que solicitaron bloqueo o renunciaron a la asignatura en la clase de lunes ascendió a 15 (31.25\%) estudiantes, 7 (15.55\%) en la clase del martes y 9 (24.33\%) en clase del sábado. También se destaca la relación entre las tasas de deserción y reprobación, las cuales apuntan a que en la clase del lunes, donde la tasa de reprobación de $20.83 \%$ fue la más baja registrada; también se observó un gran porcentaje de abandonos, el cual fue de $27.08 \%$. La clase del martes fue la que tuvo la tasa más alta (40\%) de reprobación, mientras que comparado con los otros dos grupos, obtuvo la menor tasa de abandono, totalizada en $11.11 \%$ en comparación con las otras clases.
Destacamos que no hubo alumnos con ausencias excesivas o cancelación de la inscripción de la asignatura en cualquiera de las tres clases. Se observa aquí que la tutora titular trabajó en el salón de clase con el profesor de la asignatura los días lunes y sábados, ayudando a los estudiantes que tenían dudas en el momento de los ejercicios propuestos por el profesor. Estos datos pueden indicar que el trabajo del tutor en la clase, en colaboración con el profesor de la asignatura, puede contribuir positivamente al éxito de los estudiantes.

Otros datos importantes que fueron identificados en el análisis: de los 130 estudiantes matriculados en Cálculo Diferencial e Integral I en el primer semestre de 2014, 36 estudiantes buscaron tutoría programada, de un total de 153 procesos tutoriales durante el semestre; de los cuales, $69.44 \%$ (25) obtuvo la aprobación en la signatura, $27.77 \%$ (10) fueron reprobados y el $2,78 \%$ (1) fue reprobado por no haber realizado el examen final. 
Es importante apuntar que 5 de los 10 estudiantes reprobados utilizaron el servicio de tutoría una sola vez. Esto puede representar la búsqueda de ayuda cerca de la prueba y no de forma constante. Teniendo en cuenta que el aprendizaje es un proceso continuo, estos datos están en línea con los estudios que indican la importancia del tiempo y el esfuerzo invertido en estudios para el éxito en el aprendizaje (Pace, 1984).

\section{Consideraciones finales}

Dado el significativo aumento de las matrículas en la educación superior, en paralelo con las altas tasas de deserción, es necesario que las instituciones adopten medidas que garanticen la permanencia de los estudiantes y su efectivo aprendizaje.

Al proponer programas como la tutoría programada o la tutoría en clase, la institución de educación superior, presentada en este estudio, está desplegando medidas preventivas que buscan reducir las tasas de reprobación o deserción estudiantil, una vez que la tutora auxilia el trabajo del docente en el salón de clase.

Los resultados de este estudio evidencian la necesidad de analizar continuamente la estructuración de estrategias que faciliten el aprendizaje y confirma la importancia de nuevas investigaciones en esta temática, para poder comprender los elementos que efectivamente contribuyen para la permanencia y éxito de los estudiantes en la educación superior.

En este sentido, algunos aspectos son esenciales para el aprendizaje de los estudiantes, incluyendo el compromiso y organización con el tiempo de dedicación a los estudios.

Los datos y análisis anteriores muestran la importancia de la labor de apoyo y tutoría a los estudiantes, asociado con su interés y esfuerzo

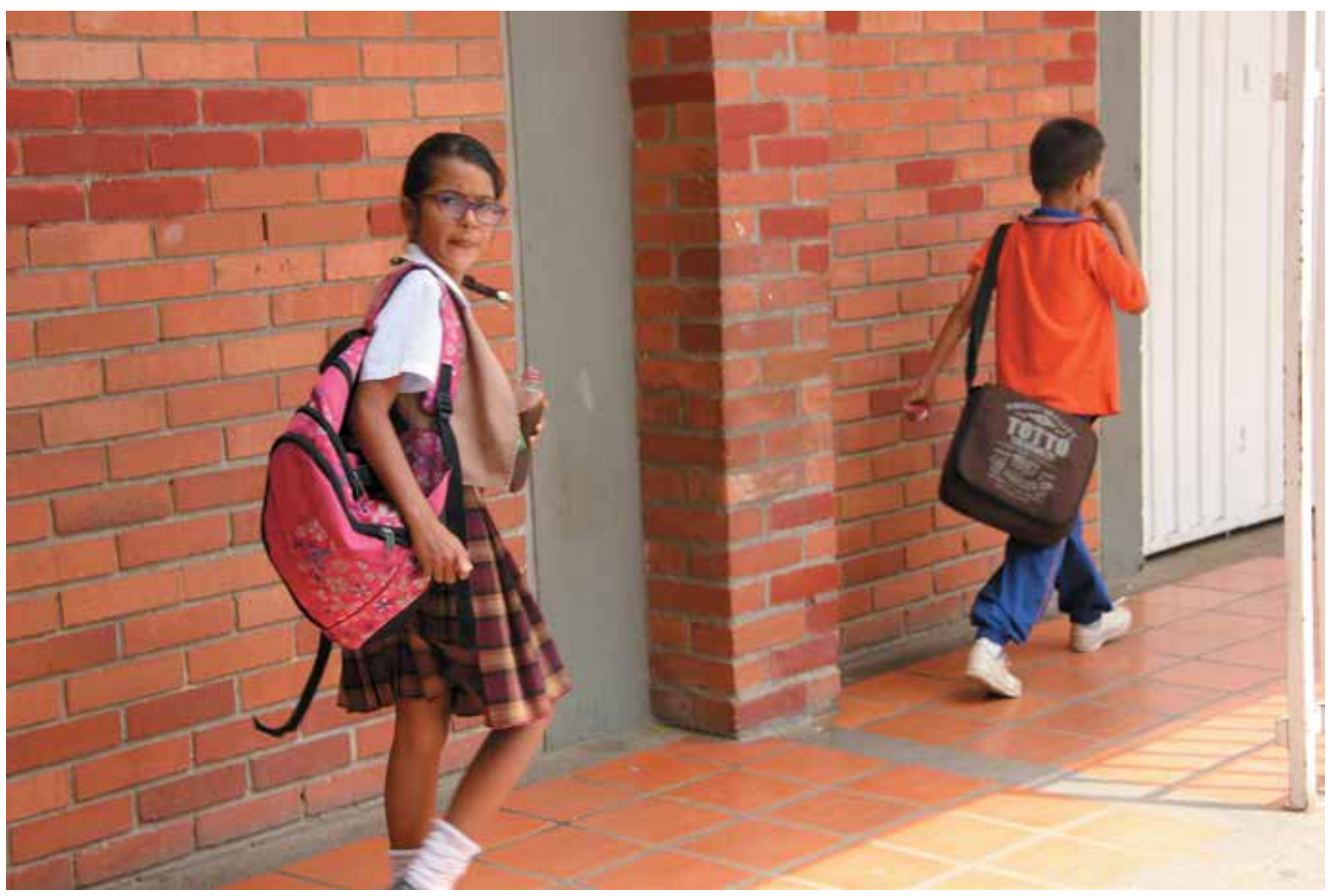


por aprender, o sea, dar sentido al aprendizaje, no solo "aprender" para la prueba. Por lo tanto, el trabajo de tutoría es una excelente estrategia implementada en la universidad, que estructurada a partir de un trabajo junto con el docente en el salón de clase, donde los dos ayudan a los estudiantes cuando ellos están haciendo los ejercicios y cuando tienen dudas. La organización de las clases y del contenido es de la responsabilidad del docente. En cuanto a la posibilidad de programar las horas de tutoría fuera de la clase, ellas ofrecen mayores opciones a los estudiantes para organizar su tiempo de estudio. En otras palabras, los estudiantes cuando saben que tienen una persona para ayudarles con los ejercicios fuera del aula pueden ir desarrollando poco a poco el hábito de la organización para estudiar, y como el servicio de tutoría es individual la tutora les instruye con estrategias de estudio. Es decir, además de estudiar con el tutor, él ofrece estrategias sobre cómo estudiar.

\section{Referencias bibliográficas}

Cury, H. N. (2004). Professora, eu só errei um sinal!: como a análise de erros pode esclarecer problemas de aprendizagem. In Cury, H. N. (Org.). Disciplinas matemáticas em cursos superiores: reflexões, relatos, propostas, (111-138). Porto Alegre, RS: EDIPUCRS.

Decreto no. 8.659 de 5 de abril de 1911. Aprova a lei Orgânica do Ensino Superior e do Fundamental na Republica. Diário Oficial da União. Rio de Janeiro, 05 de abril de 1911. Disponível em: <http://www6.senado. gov.br/legislacao/ListaPublicacoes.action?id=58698 htm> Acesso em: 12 de ago. 2009.

Decreto $\mathrm{n}^{\circ}$ 6.096, de 24 de abril de 2007. Institui o Programa de Apoio a Planos de Reestruturação e Expansão das Universidades Federais - REUNI. Presidência da República. Brasília, DF: Diário Oficial da União de 25.04.2007.

Felicetti, V. L., Fossatti, P. (jan. - mar. 2014). Alunos ProUni e não ProUni nos cursos de licenciatura: Evasão em foco. Educar em Revista, (51), 265-282. Editora UFPR. Disponible en: http://ojs.c3sl.ufpr.br/ojs2/index.php/ educar http://www.scielo.br/pdf/er/n51/n51a16.pdf

Felicetti, V. L., Giraffa, L. M. M. (2012). Matofobia: Auxiliando a enfrentar este problema no contexto escolar. Livro Digital. Porto Alegre: EDIPU.

Gay, L. R., Mills, G. E., Airasian, P. W. (2009). Education Research: Competencies for Analysis and Aplications. (9a ed.). Upper Saddle River, N.J.: Merrill/Pearson.

MEC/INEP/DEED (2013). Censo da Educação Superior 2011: resumo técnico. Brasília, Distrito Federal.

Pace, C. R. (1984). Measuring the quality of college student experiences: An account of the development and use of the college student experiences questionnaire. Los Angeles: Higher Education Research Institute.

Rossato, E. (2006). A expansão do Ensino Superior no Brasil: do domínio público à privatização. Passo Fundo: Universidade de Passo Fundo.

Silva, E. L. da, Menezes, E. M. (2001). Metodologia da pesquisa e elaboração de dissertação. (3a ed.). Florianópolis: Laboratório de Ensino a Distância da UFSC. 